1 NHS Assembly

Cite this as: BMJ 2021;375:n3029 http://dx.doi.org/10.1136/bmj.n3029 Published: 07 December 2021

\section{A national infrastructure plan for the NHS, social care, and public health is needed to build resilience for the future}

\author{
The time has come to recognise that spare capacity is not a sign of inefficiency, but rather necessary \\ to ensure that public services are prepared for future threats, argues Chris Ham
}

\section{Chris Ham co-chair}

An important and urgent lesson from covid-19 is the need for properly resourced public services able to deal with crises on the scale of the pandemic. Covid will not be the last national emergency of the 20 first century and if any good can come out of the challenges it has created it would be a willingness to prepare more effectively in the future. A national infrastructure plan for the NHS, social care, and public health is overdue to build up capacity in essential public services.

The need for such a plan has become more urgent following the decade of austerity in these services. The scale of the requirement is laid out in a report from the NAO showing that local authorities' spending power fell by $28.7 \%$ in real terms between 2010 and 11 and 2019-20. ${ }^{1}$ The public health grant to local authorities decreased by €o.5bn in real terms between 2015 and 16 and 2018-19. ${ }^{1}$ The NHS fared better receiving small real terms increases in the decade running up to the pandemic, but these increases were less than required to keep pace with rising demand.

The challenges facing public services have not arisen simply as a result of austerity. For many years the NHS has run hot most of the time because staffing ratios and bed numbers are lower than in most comparable countries. Annual winter crises exemplify the challenges with treatments being cancelled and patients inconvenienced because of shortages of essential hospital capacity. During the pandemic, shortages were a major concern in intensive care and at times there was a serious risk that services would be overwhelmed.

The impact of shortages has continued as the NHS has embarked on recovery from the pandemic. Pressures in urgent and emergency care are particularly visible with overcrowding in emergency departments and delays in ambulance response times causing harm to patients. Less visible, but no less real, are pressures in general practices, community services, and mental health and learning disability services, resulting in patients facing delays in receiving care and support, and staff having to deal with escalating challenges.

A national infrastructure plan would help to ensure that the NHS, social care, and public health teams are better able to deal with future emergencies as well as having the capacity needed to respond to other needs. Nowhere is this more important than in relation to staffing shortages which continue to limit the ability of public services to meet rising demand for care. Other priorities include hospital beds, critical care facilities, equipment, and investment in information technology.

In his evidence to the joint inquiry by the Health and Social Care Committee and the Science and Technology Committee in January 2021, former CEO of NHS England, Simon Stevens acknowledged the urgent need to build more resilience into public services, arguing "I think that is one of the big lessons from the pandemic. We talked about it a bit earlier in respect of extended supply chains versus domestic manufacturing capacity, but that is just one instance of the broader point, which is that resilience requires buffer, and buffer can look wasteful until the moment when it is not."2

The difficulties in providing a buffer should not be underestimated. Former cabinet office minister, Oliver Letwin, has noted that in government "The pressure to deal with real problems that are current is overwhelming. The result is that too little attention is paid, in every area, to building appropriate insurance policies against things that are uncertain."3 His views are echoed by former cabinet secretary, Mark Sedwill who added "it comes down to resource choices. Ministers, governments, spending reviews have to decide how much to invest in the insurance policy versus how much to invest in current priorities. We cannot disentangle that from the political process." 3

Letwin argues that an independent body is needed to act as a counterweight to short term thinking in the political process. Such a body-let's call it an Office for Pandemic Preparedness-would be charged with identifying the capacity needed in public services and the funding to build this capacity. Sustained investment in research and development, as argued by Sarah Gilbert and others, is also needed. A strong case can be made for separating funding for capacity building from the resources required to sustain existing services in order to avoid immediate pressures taking precedence.

The time has come for the Treasury to recognise that spare capacity is not a sign of inefficiency, but rather a necessary price to pay to ensure that public services are prepared for future threats. The alternative is to accept the need for huge increases in public spending when the next pandemic arrives, potentially even greater than the estimated $£ 340-370 b n$ expended to date on covid..$^{4}$ Maybe a multiyear insurance policy doesn't look so expensive after all. But who is in the market to buy one? 


\section{OPINION}

Competing interests: Chris Ham is co-chair of the NHS Assembly and non-executive director of the Royal Free London Hospitals NHS Foundation Trust. He writes here in a personal capacity.

Provenance and peer review: not commissioned, not peer reviewed

1 National Audit Office. Initial learning from the government's response to the COVID-19 pandemic May 2021. https://www.nao.org.uk/wp-content/uploads/2021/05/Initial-learning-from-the-governments-response-to-the-COVID-19-pandemic.pdf

2 Health and social care committee. Science and technology committee. Oral Evidence. Coronavirus Lessons learnt. January 2021. https://committees.parliament.uk/oralevidence/1588/pdf/

3 Health and social care committee. Science and technology committee. Oral Evidence. Coronavirus. Lessons learnt. December 2020. https://committees.parliament.uk/oralevidence/1323/pdf/

4 House of commons library. Public spending during the covid-19 pandemic. https://researchbriefings.files.parliament.uk/documents/CBP-9309/CBP-9309.pdf 